\title{
How dematerialization contributes to a low carbon society?
}

\author{
S. Fujimori \& T. Masui \\ Social \& Environmental Systems Division, \\ National Institute for Environmental Studies, Japan
}

\begin{abstract}
In the light of recent knowledge about the seriousness of climate change, a lot of attention is being paid to low carbon societies, which reduce their carbon emissions. On the other hand, in terms of sustainability, some countries are seeking a dematerialized society. Such a dematerialized society aims to reduce material inputs and waste discharge. The question follows as to how these two types of societies are related. Presumably, the carbon emission in a dematerialized society can be expected to be lower than in a non-dematerialized society. However, just how much lower? This study answers to this question with a quantitative analysis by using a global CGE (Computable General Equilibrium) model. The CGE model has the advantage that it can analyze a whole economic system, its energy use and $\mathrm{CO}_{2}$ emission consistently. We conduct scenario analysis using this CGE model. Four comparative scenarios are simulated; (1) business as usual without carbon emission constraints, (2) dematerialization without carbon emission constraints (3) business as usual with carbon emission constraints, and (4) dematerialization with carbon emission constraints. For each scenario $\mathrm{CO}_{2}$ emissions and material inputs for the whole society are estimated and analyzed. The time period covered is from 2005 to 2050 and the target area is the world divided into 12 regions. In this study, we focus on steel as an indicator of the dematerialization. For developing a dematerialized society scenario, we examine changes in investment and assume other materials are substituted for steel. There are two main findings. One is that dematerialization certainly reduces the $\mathrm{CO}_{2}$ emission globally, especially in Asian developing countries and reduces the carbon cost. The other is that even though dematerialization contributes to the development of a low carbon society, there still seems to be difficulties in achieving a large $\mathrm{CO}_{2}$ emission reduction.
\end{abstract}


Keywords: dematerialization, low carbon society, CGE model, steel consumption, GHG emission price.

\section{Introduction}

The Fourth Assessment Report published by Intergovernmental Panel on Climate Change (IPCC) reveals that past observed climate change is very likely induced by human activity. With the continuing improvements in global climate models, the relationship between future greenhouse gases (GHG) emissions and temperature increase is becoming clear. In addition, the future impact of the climate change on the natural ecosystem and human society is projected, within a large uncertainty range, to be highly significant. According to such scientific information, many countries are trying to reduce $\mathrm{GHG}$ emissions through initiatives such as the Kyoto protocol and the Copenhagen accord. On the other hand, we have not yet had a clear answer to following questions: (1) To what extent can we reduce GHG emissions? (2) What technologies should be developed and actually installed? (3) How much will it cost? In order to answer these questions, several integrated assessment models have been developed and applied. For instance, Clarke et al.[3] compiles around 10 research results and shows how the difficulties of climate mitigation are different depending on the $\mathrm{CO}_{2}$ concentration stabilization level (such as 450 or $550 \mathrm{ppm}$ ) and the time-path of international participation (such as whether developing countries participation is delayed or not ). Most of the models provide solutions for the $550 \mathrm{ppm}$ concentration target but not for the $450 \mathrm{ppm}$. This implies achieving what we call a low carbon society will not be so easy.

Apart from climate change, there are other global issues such as food, water and metal resource scarcity problems, which seek a sustainable development for human society. "Dematerialization" is one of the issues related to sustainable development (von Weizsaecher et al. [20]). Though "dematerialization" has not been clearly defined, it can be referred to as the process of fulfilling society's functions while decreasing the use of material resources over time (van der Voet [18]). Dematerialization can be measured on different geographical scale levels such as nations, regions, and cities. Moreover, there are a variety of methods of measuring it. At times it is measured as the mass of the total material inputs and at other times as the intensity of material inputs per driving force of an activity (Matthews et al. [11]). The target material can be the total bulk of a material or some specific elements. The latter analysis is what we call "Substantial Flow Analysis" (e.g.; Fujimori and Matsuoka [6]).

One interesting question arises: How are a low carbon society and a dematerialized society related? In terms of fossil fuel, it is easy to answer that a low carbon society is a dematerialized society since it consumes relatively less fossil fuel. However, when we consider other material consumption, we cannot answer to that question so easily. Presumably, the carbon emission in a dematerialized society can be expected to be lower than in a non-dematerialized 
society since material processing requires energy. But, just how much lower is it?

This study gives one solution to this question. We applied a global computable general equilibrium (CGE) model from 2005 to 2050 and conducted scenario analysis using 4 kinds of different scenarios. Because it is difficult to analyze all materials input to society, this study focuses only on steel consumption. There are two reasons why steel is chosen as the representative material. One is that steel is an essential material in many industries since it is used in construction, machine, and transport equipment and so on. The other is that the changes in the structure of steel consumption could have large multiplied effects on the whole of industry since the steel industry has many downstream firms. We compare 4 scenarios for energy consumption GHG emissions, steel consumption and production, and GHG emission price. We differentiate 4 scenarios by using two axes, namely, the GHG emission constraint on/off and improvement in steel consumption intensity on/off.

Here, we review the related literature. Although there are many previous studies that have analyzed global GHG emission and the cost of its mitigation so far, they have rarely taken into account such dematerialization. For instance, as is mentioned above, the special issue including Clarke et al. [3] compiles 10 model group results. They are categorized into two types of models; bottom-up and topdown. In terms of the bottom-up model, the IMAGE model (van Vliet et al. [20] takes into account decreases in material intensity. However, the others do not explicitly consider such a decrease of material usage. On the other hand, the topdown model (Blanford et al. [1]; Calvin et al. [2] and so on) has not taken into account decrease of material intensity. Focusing on the steel supply and demand analysis using a CGE model, Schumacher and Sands [14] could be pioneers of this kind of analysis. They disaggregate the steel sector by the process of the steel making and they showed mass of steel supply, demand and price up to 2050 in Germany. The Schumacher and Sands study describes the production side in detail but not demand side. Thus, this study integrates the new aspects into climate mitigation analysis especially for the global CGE model with a change in steel demand structure.

The next section presents the overall method used for this analysis. Section 3 contains the results of the application of the method, while section 4 shows a sensitivity analysis for improvement in steel consumption intensity. Section 5 discusses uncertainties underlying the model and the assumptions. Finally, this paper is concluded in section 6 .

\section{Methodology}

\subsection{Overview of the method}

An overview of the methodology is shown in Figure 1. Four scenarios, called scenario A, B, C and D, were prepared. Scenario A is what we call the business as usual case and it has no GHG emission constraint or steel consumption 


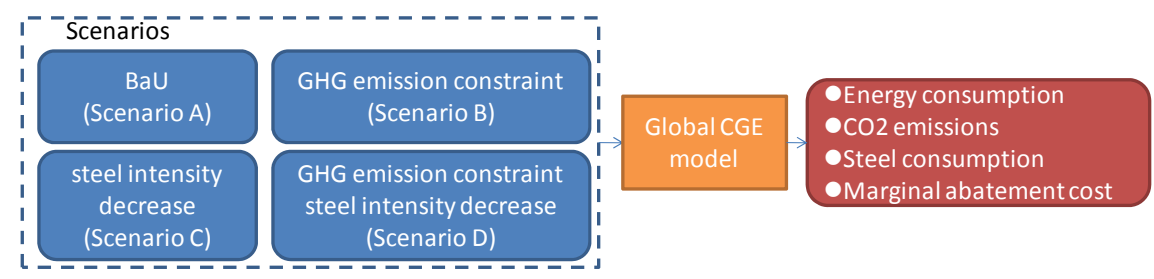

Figure 1: Overview of the method.

structure change. Scenario B includes the GHG emission constraint from scenario A. Scenario C contains steel consumption structure change. Scenario D considers both of them. Secondly, a global CGE model is developed and applies to these scenarios. This CGE model is a dynamic recursive general equilibrium model that covers the whole world. To analyze climate mitigation and its technological change, the power sector is disaggregated in very detailed levels (14 sectors). The CGE model has the advantage that it can consistently simulate the whole social economic activity. This implies that when some sort of structural change occurs in a sector the multiplied effect can be analyzed with consistency. This study focuses mainly on steel consumption, energy consumption, GHG emission and GHG emission price. First the CGE model is explained, next the main assumptions made for the 4 scenarios, and finally the scenarios themselves are described in detail.

\subsection{CGE model}

This CGE model is a dynamic recursive general equilibrium model that includes multi-regions and multi-sectors. The calculation time step is one year. The classifications of regions and sectors are shown in Table 1 and Table 2. The region classification is based on geographical regions. However, China and India are separated since they will play an important role in the world economy. There are 36 industrial classifications but half are energy sectors.

The calibration data is Fujimori and Matsuoka (forthcoming) [7]. This database consists of world social accounting matrices and energy balance tables which are calculated using international industrial statistics (OECD[13]; IISI [10] etc), trade statistics (UN [16]), national accounts (UN [15]), energy statistics (IEA [9]) and Input-output tables (Dimaranan [5]; OECD [12]).

The actors in the CGE model decide their production, consumption, investment and trade activities using their own behavioural functions and market prices. The whole model structure is shown in Figure 2.

There are four blocks: production, income distribution, final consumption, and market. The first block, production, represents the structure of the

Table 1: Region classification.

\begin{tabular}{|l|l|l|l|l|l|l|l|}
\hline XOC & Oceania & IND & India & XLM & $\begin{array}{l}\text { Central \& } \\
\text { South America }\end{array}$ & CIS & $\begin{array}{l}\text { Former Soviet } \\
\text { Union }\end{array}$ \\
\hline JPN & Japan & XSA & Rest of Asia & XE25 & EU & XME & Middle East \\
\hline CHN & China & XNA & North America & XER & Rest of Europe & XAF & Africa \\
\hline
\end{tabular}


Table 2: Industry classification.

\begin{tabular}{|l|l|l|l|}
\hline \multicolumn{2}{|c|}{ Non-energy sectors(17) } & \multicolumn{2}{|l|}{ Energy Sector (19) } \\
\hline AGR & Agriculture & COA & Coal mining \\
\hline FRS & Forestry & OIL & Oil mining \\
\hline OMN & Mineral mining and Other quarrying & GAS & Gas mining \\
\hline FPR & Food products & P_C & Petroleum and coal refinery \\
\hline TEX & Textiles and Apparel and Leather & E_COL & Coal-fired without CCS \\
\hline LUM & Wood products & E_GAS & Oil-fired without CCS \\
\hline PPP & Paper, Paper products and Pulp & E_OIL & Gas-fired without CCS \\
\hline CRP & Chemical, Plastic and Rubber products & EC_COL & Coal-fired with CCS \\
\hline NMM & Mineral products nec & EC_GAS & Oil-fired with CCS \\
\hline I_S & Iron and Steel & EC_OIL & Gas-fired with CCS \\
\hline NFM & Non Ferrous products & E_HYD & hydroelectric power \\
\hline MCH & Machinery & E_NUC & nuclear electric power \\
\hline TRN & Transport equipment & E_SPV & photovoltaic power \\
\hline OMF & Other Manufacturing & E_WIN & wind-power \\
\hline CNS & Construction & E_GEO & geothermal power \\
\hline TRS & Transport and communications & E_BIO & biomass-power without CCS \\
\hline CSS & Service sector & EC_BIO & biomass-power with CCS \\
\hline & & E_ORN & other renewable energy power \\
\hline & & GDT & Gas manufacture distribution \\
\hline
\end{tabular}

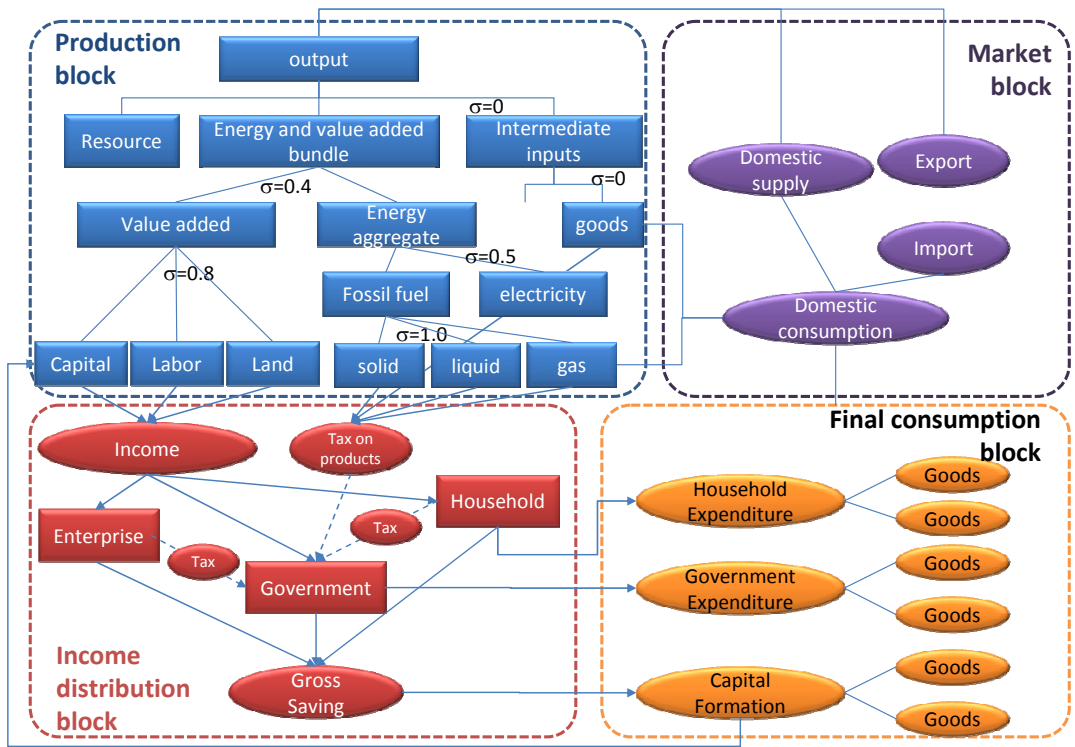

Figure 2: $\quad$ CGE model structure.

production functions. We apply a nested CES function for production activities with multiple nested CES functions. The output requires natural resource, intermediate inputs, of non-energy goods as determined by fixed coefficients, and an energy-value added bundle. The energy and value-added bundle is nested by value added and energy aggregation. Value added is composed of capital, labour and land inputs. On the other hand energy aggregation is firstly composed 
of fossil fuel and electricity. The fossil fuel is again nested according to three types of fuel. The elasticity of the CES functions is shown in the figure. Needless to say, the fossil fuels combustion produces $\mathrm{CO}_{2}$ emission as follows.

Second, incomes are distributed to three institutional sectors; namely, enterprises, government, and households. The government takes in income by collecting taxes. Third, institutions consume goods as final consumption. Government expenditure and capital formation are defined as a constant coefficient function. The LES (Linear Expenditure System) function is used for household consumption. Lastly, the CES function is applied to the import of goods and the CET function is applied to the export of goods. A goodsconsumption-and-supply equilibrium is achieved for each market.

\subsection{Assumptions}

Some future scenario assumptions are included in all 4 scenarios. In this section, we show population, labour force, GDP growth rate, AEEI (Autonomous Energy Efficiency Improvement), and productivity improvement.

\subsubsection{Population, labour force, GDP ans AEEI}

Labour force, which is one of the production factors, is assumed to be proportional to population change. The medium estimation of UN population prospects (UN [17]) is used for the future population change. The GDP growth rate is shown in Table 3. We use AEEI as Table 4.

Table 3: $\quad$ Annual growth rate of GDP for each region.

\begin{tabular}{cccccccccccccc}
\hline & XOC & JPN & CHN & IND & XSA & XNA & XLM & XE25 & XER & CIS & XME & XAF & World \\
\hline $2005-2010$ & 3.3 & 0.4 & 5.9 & 5.0 & 4.7 & 2.5 & 2.7 & 1.8 & 2.0 & 3.5 & 3.4 & 2.9 & 3.2 \\
$2010-2020$ & 2.4 & 0.2 & 6.6 & 5.4 & 4.4 & 2.0 & 3.1 & 1.6 & 1.8 & 3.4 & 4.6 & 3.6 & 3.7 \\
$2020-2030$ & 1.8 & 0.3 & 6.7 & 5.5 & 3.6 & 1.9 & 3.3 & 1.3 & 1.8 & 2.7 & 4.6 & 4.1 & 4.1 \\
$2030-2040$ & 1.5 & 0.1 & 5.1 & 5.2 & 2.8 & 1.4 & 3.1 & 1.1 & 1.8 & 2.3 & 3.4 & 4.4 & 3.6 \\
$2040-2050$ & 1.1 & 0.2 & 2.9 & 5.0 & 2.1 & 1.0 & 2.7 & 0.8 & 1.6 & 2.0 & 3.0 & 4.2 & 2.6 \\
\hline
\end{tabular}

Table 4: $\quad$ AEEI annual change rate.

\begin{tabular}{cccccccc}
\hline Region & XNA & EU25 & JPN & XOC & CHN & IND & Other regions \\
\hline Annual growth rate(\%) & 1.30 & & 1.21 & & 1.98 & 1.43 & 1.21 \\
\hline
\end{tabular}

\subsubsection{Productivity improvement}

The productivity of each industry is calculated by dynamical calibration. In other words, the efficiency parameter of CES function of a value-added bundle is estimated dynamically year by year. When we calculate a year, we have the next years expected GDP targets, labour inputs and capital stocks. To achieve the GDP targets, we re-calculate the efficiency parameter as follows.

The CES function of a value-added bundle is defined as

$$
Q V A_{r, a}=\alpha_{r, a} \cdot\left(\sum_{f \in F} \delta_{r, a} \cdot Q F_{r, f, a}{ }^{-\rho_{r, a}}\right)^{-\frac{1}{\rho_{r, a}}}, \quad \forall r \in R, a \in A
$$


$Q V A_{r, a}:$ quantity of (aggregate) value-added, $Q F_{r, f, a}$ : quantity demanded of factor $f$ from activity $a, \alpha_{r, a}$ : efficiency parameter in the CES value-added function, $\delta_{r, a}$ : CES value-added function share parameter for factor $f$ in activity $a, \rho_{r, a}$ : CES value-added function exponent, and $R, F$ and $A$ denote region, factor and sectors for each.

There is expected growth rate of the value added, and we can calculate the revised efficiency parameter $\alpha_{r, a}{ }^{*}$ as

$$
\alpha_{r, a}{ }^{*}=Q V A_{r, a}^{t-1} \cdot g g r_{r}^{t^{*}} /\left(\sum_{f \in F} \delta_{r, a} \cdot\left(Q F_{r, f, a}^{t-1} \cdot f g r_{r, f}^{t}\right)^{-\rho_{r, a}}\right)^{-\frac{1}{\rho_{r, a}}}, \forall r \in R, a \in A C
$$

$\alpha_{r, a}^{v a{ }^{*}}:$ revised efficiency parameter in the CES value-added function, $g g r_{r}{ }^{*}$ : expected GDP growth target (annual growth rate), $f r_{r, f}^{t}$ : expected factor input growth rate, $t$ denotes set of year.

\subsection{Scenario description}

As is already shown, this study applies 4 scenarios.

Scenario A is the business as usual case and it only considers the assumptions explained in the previous section.

Scenario B has a $\mathrm{CO}_{2}$ emission constraint. In this study, we selected the $\mathrm{CO}_{2}$ emission constraint as $550 \mathrm{ppm} \mathrm{CO}_{2}$ equivalent concentration stabilization. Generally, climate mitigation model studies often analyze 450 and $550 \mathrm{ppm}$ concentration stabilization. However, Clarke et al. [3] showed $450 \mathrm{ppm}$ was achievable only by a few studies but most declared it was impossible. Therefore, we think that the $550 \mathrm{ppm}$ scenario is comparatively more realistic than the 450ppm scenario. Although we set the stabilization target, there was still the problem that the stabilization pathway could not be determined to be unique only with that stabilization target. Therefore, we borrowed the pathway from Hijioka et al. [8]. Moreover, in this study we take into account only $\mathrm{CO}_{2}$ emissions from fossil fuel as GHG emission. A concrete pathway is shown in a latter section along with a graph.

Scenario $\mathrm{C}$ considers improvement in steel consumption intensity but not the $\mathrm{CO}_{2}$ emission constraint. The term improvement in steel consumption intensity is defined as steel consumption per unit production for each industry in this study.

Scenario D implements both improvement in steel consumption intensity and the $\mathrm{CO}_{2}$ emission constraint. In order to answer the primary question, the main focus should be on the comparison between scenario $\mathrm{B}$ and $\mathrm{D}$. When the emission reduction cost is compared between them, we can see how the dematerialization contributes to the $\mathrm{CO}_{2}$ emission reduction. The CGE model calculates the $\mathrm{CO}_{2}$ emission reduction cost like carbon tax. The higher the emission cost is, the larger the burden of the mitigation becomes.

The improvement in steel consumption intensity is assumed to be the industrial sector's intermediate input coefficient decreasing constantly from 2010. The annual decrease rate is assumed as below. We only consider this 
Table 5: $\quad$ Annual steel consumption intensity improvement (\%).

\begin{tabular}{|c|c|c|}
\hline Machinery & Transport equipment & Construction \\
\hline $\mathrm{MCH}$ & TRN & CNS \\
\hline 5.9 & 3.5 & 2.1 \\
\hline
\end{tabular}

intensity improvement for machinery, transport equipment and construction sectors since they represent most of the demand for steel.

These improvement rates come from Japan's numerical evidence from Committee on iron and steel statistics [4] and STAN Database (OECD [13]). The Committee on iron and steel statistics [4] contain steel order volume for each sector and the STAN Database (OECD[13]) has industrial output indexes. The steel consumption per unit production was then plotted as in Figure 3. Each industry experienced improvement in steel consumption intensity over the past three decades. This decrease is probably due to the substitution of steel with other materials such as plastics. However, we could not confirm that substitution with the evidence so far. Thus, we assume that the decrease in steel use would be homogenously replaced by the other material inputs. Technically this means that we did not change the production structure but did change the parameters of intermediate inputs.

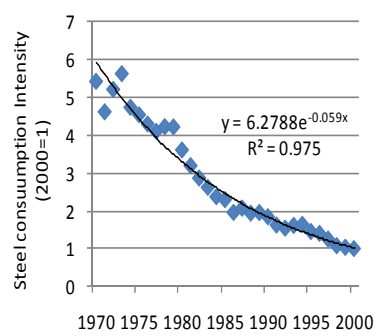

Machinery (a)

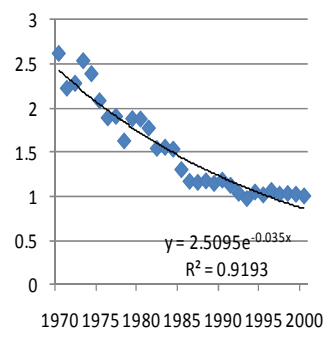

Transport equipment (b)

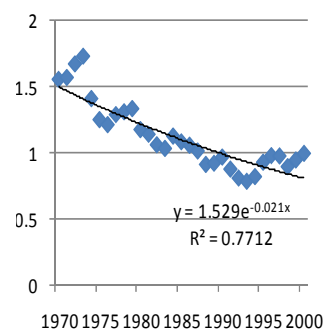

Construction (c)

Figure 3: Japan's improvement in steel consumption intensity.

\section{Results}

\subsection{Steel sector production, energy consumption and $\mathrm{CO}_{2}$ emission}

Global steel production is compared among 4 scenarios (Figure 4(a)). Scenario A and $\mathrm{B}$ (without improvement in steel intensity) shows similar trajectory as do scenario $\mathrm{C}$ and $\mathrm{D}$ (with improvement in steel intensity). The former two scenarios are quite different from the latter. This implies that steel production is affected not so much by $\mathrm{CO}_{2}$ emission control but by the assumption of improvement in steel consumption intensity. Looking at the regional breakdown in scenario D (Figure 4(b)), you can see that China dominates steel production and this tendency is more apparent in 2050. India also increases its world share by 2050 . 
Next, the steel sector's energy consumption and $\mathrm{CO}_{2}$ emission are shown (Figure 5). These two graphs show similar trajectories. The $\mathrm{CO}_{2}$ constrained cases (scenario $\mathrm{B}$ and D) are comparatively lower than the $\mathrm{CO}_{2}$ free cases (scenario $\mathrm{A}$ and $\mathrm{C}$ ). There is an interesting point in that scenario $\mathrm{A}$ and scenario B will be quite different by 2050 but steel production is almost same. This is due to the energy price increase coming from the $\mathrm{CO}_{2}$ emission cost and substitution of the energy for other production factors such as capital.
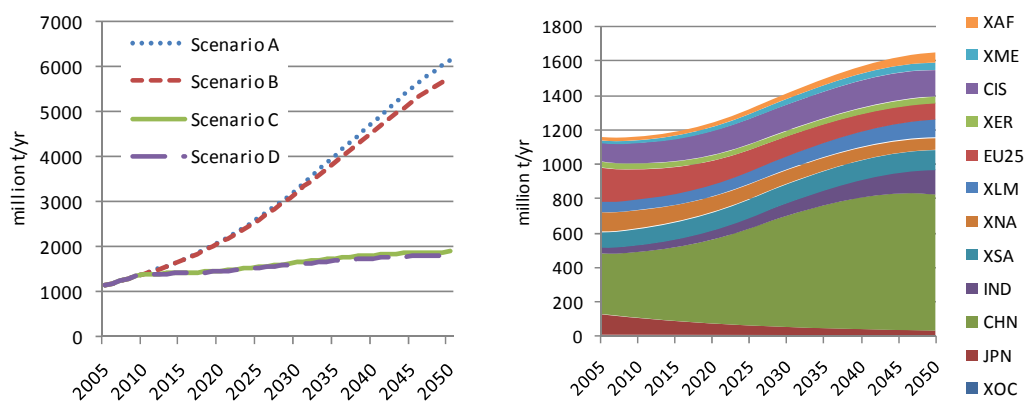

Steel production by scenarios (a) Steel production of scenario D by region (b)

Figure 4: $\quad$ Steel production.

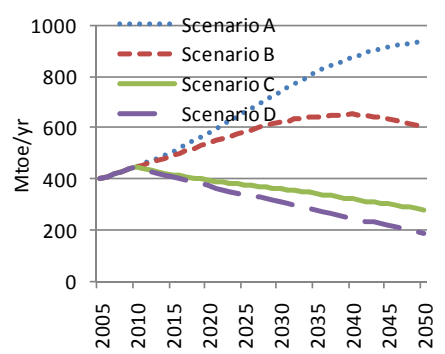

Energy consumption (a)

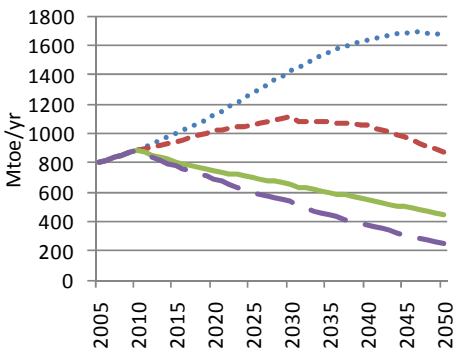

$\mathrm{CO}_{2}$ emission (b)

Figure 5: $\quad$ Steel sector energy consumption and $\mathrm{CO}_{2}$ emission.

\section{2 $\mathrm{CO}_{2}$ emission}

Next $\mathrm{CO}_{2}$ emission is analyzed. Figure 6 (a) shows the pathway of global $\mathrm{CO}_{2}$ emissions. Scenario B and D are same since they have to satisfy the exogenous $\mathrm{CO}_{2}$ emission constraint pathway. In 2050, $550 \mathrm{ppm}$ stabilization scenarios are supposed to achieve around a 25\% emission reduction compared to 2005 . Looking at scenarios $\mathrm{A}$ and $\mathrm{C}$, scenario $\mathrm{C}$ shows a reduction a little bit lower than scenario A (4\% lower in 2050). Figure 6(b) shows this reduction by regions. As you can easily see, China's reduction is very large. 


\section{3 $\mathrm{CO}_{2}$ emission price}

As already explained, the $\mathrm{CGE}$ model gives us a $\mathrm{CO}_{2}$ emission price like a carbon tax. Figure 7(a) shows the $\mathrm{CO}_{2}$ emission price of the $\mathrm{CO}_{2}$ constrained scenarios (scenario $\mathrm{B}$ and $\mathrm{D}$ ). Scenario D's $\mathrm{CO}_{2}$ emission price would be 376 $\left(2005 \mathrm{US} \$ / \mathrm{tCO}_{2}\right)$ in 2050. On the other hand scenario B shows 433 $\left(2005 \mathrm{US} \$ / \mathrm{tCO}_{2}\right)$ for the same time. It equals a $13 \%$ price reduction. Moreover, scenario $\mathrm{C}$ is consistently lower priced than scenario $\mathrm{B}$ in time-series. This means that the dematerialization does certainly contribute to the low carbon society, though the $\mathrm{CO}_{2}$ emission price is still high.

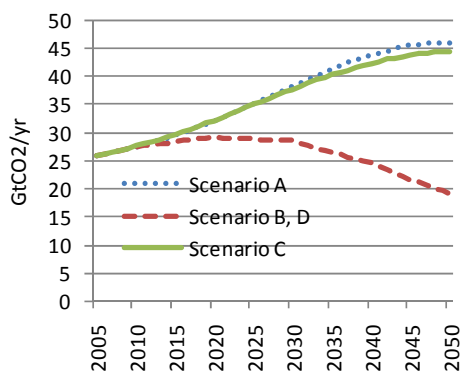

Global $\mathrm{CO}_{2}$ emission (a)

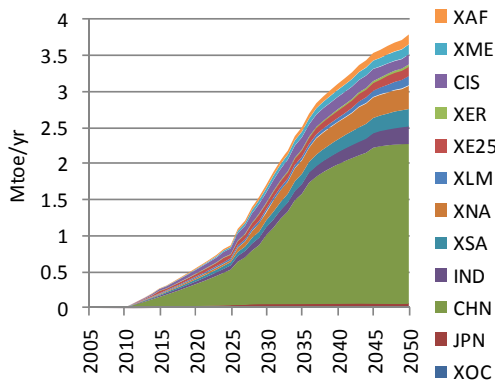

$\mathrm{CO}_{2}$ reduction of scenario $\mathrm{C}(\mathrm{b})$

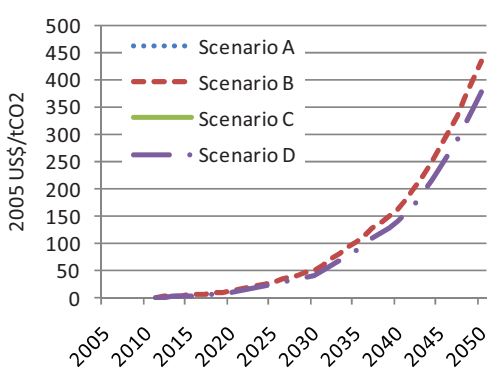

(a) Comparison of scenarios
$\mathrm{CO}_{2}$ emission.

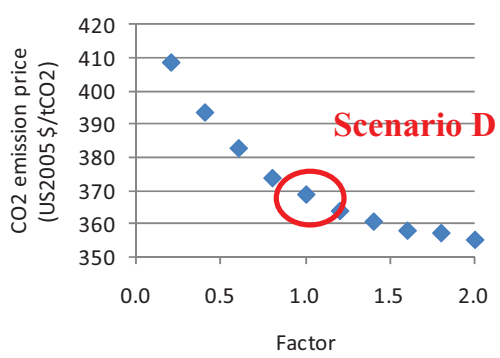

(b) sensitivity analysis

Figure 7: $\quad \mathrm{CO}_{2}$ emission price.

\subsection{Sensitivity analysis}

The rate of improvement in steel intensity is set with a large assumption because we now only have the information for Japan's case. Thus, we control the improvement in intensity rate from half to twice the rate in Table 5 for scenario D. Figure 7(b) represents the sensitivity analysis results. This graph has factors of $1 / 2$ to 2 on the horizontal axis and the $\mathrm{CO}_{2}$ emission price in 2050 on vertical axis. As is shown in this figure, $\mathrm{CO}_{2}$ emission price decreases as the increase in the improvement rate. However, the $\mathrm{CO}_{2}$ emission price decrease slows down. This implies that even if we could achieve more intensive dematerialization, the difficulties of $\mathrm{CO}_{2}$ emission reduction would not change so much. 


\section{Discussions}

There are 4 points we would like to discuss with regard to the uncertainties and limitations of this study. Firstly, we implemented a bold assumption in improvement of steel consumption intensity as mentioned in the previous section. We obtained the improvement rate from Japan's sample and applied it to the other regions. Although we checked the sensitivity of the assumption, we could not depict that for regional differences. This is one of the uncertainties in this study. If we could obtain such information for developing countries it would greatly contribute to the reduction of this uncertainty. We leave this work for the future study. Secondly, this study only treats energy oriented $\mathrm{CO}_{2}$ as $\mathrm{GHG}$ because we want to know the direct reaction of the $\mathrm{CO}_{2}$ emission change from fossil fuel combustion. However, this energy related $\mathrm{CO}_{2}$ emission is only $60 \%$ of all GHG emission, so if other gases are considered, the results would be a little different. Thirdly, the CGE is a top-down model and steel demand is represented as an input-output coefficient. On the other hand a bottom-up study could represent a more concrete steel demand and give different results. Finally, this study chose steel as an indicator of the dematerialization. Although steel is an essential material, society is actually sustained by various materials other than steel. The real term of dematerialization should be discussed with reference to such other materials.

\section{Conclusion}

This study describes one of the aspects of a dematerialized society and low carbon society with using a global CGE model and showed that dematerialized society can quantitatively contribute to a low carbon society. It considers a scenario stabilizing at a concentration of $550 \mathrm{ppm} \mathrm{CO}_{2}$ by 2050, and takes into account an improvement in steel consumption intensity. Assuming Japan's past improvement in steel intensity extends over the next 4 decades, the $\mathrm{CO}_{2}$ price could reduce by $13 \%$. However, the improvement in intensity effect would slow down, even if we see stronger improvement in steel intensity. Therefore, dematerialization contributes to low carbon society to a certain extent but still there seems to be difficulties in achieving large $\mathrm{CO}_{2}$ emission reductions. Although this study includes a large amount of uncertainty and limitations, we could demonstrate an interesting dimension in terms of sustainable development. This study can be a guide for future research.

\section{References}

[1] Blanford, G.J., Richels, R.G. \& Rutherford, T.F., Feasible climate targets: the roles of economic growth, coalition development and expectations. Energy Economics 31, ppS82-S93, 2009

[2] Calvin, K., Patel, P., Fawcett, A., Clarke, L., Fisher-Vanden, K., Edmonds, J., Kim, S.H., Sands, R. \& Wise, M., The distribution and magnitude of emissions mitigation costs in climate stabilization under less than perfect international cooperation: SGM results, Energy Economics, 31, pp.S187S197, 2009. 
[3] Clarke L., Edmonds J., Krey V., Richels R., Rose S. \& Tavoni M., International climate policy architectures: Overview of the EMF 22 International Scenarios, Energy Economics, 31, pp.S64-S81, 2009.

[4] Committee on iron and steel statistics, Handbook for iron and steel statistics, Commitee on iron and steel statistics, 2006.

[5] Dimaranan, B.V., Global Trade, Assistance, and Production: The GTAP 6 Data Base. Center for Global Trade Analysis, Purdue University, 2006.

[6] Fujimori S. \& Matsuoka Y., Development of estimating method of global carbon, nitrogen, and phosphorus flows caused by human activity, 62(3-4), pp399-418, 2007.

[7] Fujimori S. \& Matsuoka Y., Integration of economic and energy information for global economic and energy model simulation, forthcoming.

[8] Hijioka Y., Matsuoka Y., Nishimoto H., Masui T. \& Kainuma M., Global GHG emission scenarios under GHG concentration stabilization targets. J. Global Environ. Eng., 13, pp.97-108, 2008

[9] International Energy Agency (IEA), Energy balances for OECD countries, International Energy Agency, Paris, France, 2009.

[10] International Iron and Steel Institute (IISI), Steel Statistical Yearbook, IISI, 2009.

[11] Matthews E., Bringezu S., Fischer-Kowalski M., Huetller W., Kleijn R., Moriguchi Y., Ottke C., Rodenburg E., Rogich D., Schandl H., Schuetz H., van der Voet E. \& Weisz H., The Weight of Nations, Material Outflows from Industrial Economies, World Resources Institute, Washington, 2000.

[12] Organization for Economic Co-operation and Development (OECD), Inputoutput tables, OECD, Paris, France, 2010.

[13] Organization for Economic Co-operation and Development (OECD), STAN Database for Structural Analysis, OECD, Paris, France, 2005.

[14] Schumacher K. \& Sands R.D., Where are the industrial technologies in energy-economy models? An innovative CGE approach for steel production in Germany

[15] United Nations (UN), National Accounts Main Aggregates Database, New York, USA, 2007.

[16] United Nations (UN), United Nations Commodity Trade Statistics Database, United Nations, New York, USA, 2006.

[17] United Nations (UN), World Population Prospects: 2008 Revision Population Database, United Nations, New York, USA, 2007.

[18] van der Voet E., van Oers L. \& Nikolic I., Dematerialization: Not Just a Matter of Weight, Journal of Industrial Ecology, 8(4), pp.121-137, 2004.

[19] van Vliet, J., den Elzen, M.G.J. \& van Vuuren, D.P., Meeting radiative forcing targets under delayed participation. Energy Economics 31, pp.S152S162, 2009.

[20] von Weizsaecker, E., Lovins A. B., \& L. H. Lovins., Factor four, doubling wealth, halving resource use. The new report to the Club of Rome. London: Earthscan Publications, 1997. 